\title{
Morphological changes of isotactic poly(methyl methacrylate) thin films via self-organization and stereocomplex formation
}

\author{
Daisuke Kamei $^{1}$, Hiroharu Ajiro ${ }^{1,2}$ and Mitsuru Akashi ${ }^{1,2}$
}

Morphological changes of macromolecularly porous thin films during isotactic (it) poly(methyl methacrylate) (PMMA) crystallization and the subsequent syndiotactic (st) poly(methacrylic acid) (PMAA) incorporation are described herein. Porous it-PMMA thin films were prepared on a gold substrate by the selective extraction of st-PMAA from stereocomplex films composed of it-PMMA/st-PMAA using layer-by-layer assembly. it-PMMA crystallization occurred when the porous it-PMMA films were immersed in a mixed solvent of acetonitrile/water $(4 / 6, \mathrm{v} / \mathrm{v})$. Surface analyses of films were performed by scanning electron microscopy, atomic force microscopy, X-ray photoelectron spectroscopy (XPS) and static contact angles. Dotted aggregates of it-PMMA appeared on crystallized films, whereas networks composed of crystallized it-PMMA and the stereocomplex were observed on st-PMAA incorporated films. Gold substrate peaks were observed not on porous it-PMMA films, but on crystallized it-PMMA films by XPS, indicating that homogeneously broadened it-PMMA in porous films was localized because of its crystallization. The static contact angle of crystallized it-PMMA films was $36.5 \pm 1.6^{\circ}$, which was smaller than that of porous it-PMMA films $\left(49.2 \pm 1.9^{\circ}\right)$. This difference resulted from the surface morphology of the thin films. Dotted it-PMMA aggregates were also observed when spin-coated films were immersed in the mixed solvent.

Polymer Journal (2010) 42, 131-137; doi:10.1038/pj.2009.324; published online 23 December 2009

Keywords: layer-by-layer assembly; nanostructure; poly(methyl methacrylate); self assembly; stereocomplex; thin film

\section{INTRODUCTION}

Stereoregular poly(methyl methacrylate)s (PMMA) have attracted much attention because of their unique crystalline structure, morphology, and other particular properties since the first report by Stroupe and coworkers. ${ }^{1}$ Isotactic (it) PMMA and syndiotactic (st) PMMA can self-aggregate either by themselves or as stereocomplexes. it-PMMA crystals form a double-stranded helical structure, ${ }^{2}$ whereas st-PMMA does not crystallize, but includes specific organic solvents in a cavity within its single-stranded helix. ${ }^{3}$ The stereoregular PMMA stereocomplex is a complementary helical structure formed on the basis of structural fitting between two chains of it-PMMA and st-PMMA. ${ }^{4-6}$ Recently, the discussion has arisen on the basic structure of the PMMA stereocomplex by using X-ray ${ }^{7}$ and atomic force microscopy (AFM), 8,9 although it was concluded that the structure of the stereocomplex is a helix with it-PMMA on the inside surrounded by st-PMMA.

Interfacial rearrangements of $i$-PMMA chains are expected to occur more easily than st-PMMA or atactic-PMMA chains, because the glass transition temperature of it-PMMA $\left(\sim 40^{\circ} \mathrm{C}\right)$ is significantly lower than that of $s t$-PMMA or atactic-PMMA (around $105-135^{\circ} \mathrm{C}$ ). ${ }^{10}$ The crystallization of it-PMMA films has been researched by annealing at elevated temperatures for more than a few days, or under compres- sion. ${ }^{11-19}$ Most of these studies focused mainly on structural analyses of the crystals using infrared (IR) spectroscopy and X-ray diffraction (XRD), but the morphology of crystallized it-PMMA films has also been studied for a long time. ${ }^{11,12,16,18}$ The film-formation methods used were either solvent evaporation from solution-cast films or the Langmuir-Blodgett technique as described below. Over 30 years ago, Klement and Geil ${ }^{11}$ studied the lamellar growth of it-PMMA cast films annealed at a narrow temperature range $\left(55-65^{\circ} \mathrm{C}\right)$ with electron microscopy, whereas Challa and coworkers ${ }^{12}$ observed the macroscopic hexagonal structures of crystallized it-PMMA from casts at 90-130 ${ }^{\circ} \mathrm{C}$ using a polarization microscope. Later, Brinkhuis and Schouten ${ }^{16}$ demonstrated the epitaxial crystallization in it-PMMA cast films covered by Langmuir-Blodgett overlayers. Recently, Yashima and coworkers ${ }^{18}$ directly observed two-dimensional folded-chain crystals of it-PMMA monolayers obtained by Langmuir-Blodgett deposition using AFM.

In contrast, macromolecularly porous it-PMMA thin films have been studied as a scientifically important model, as they have strictly controlled nanospaces and were utilized for specific molecular recognition or precise reaction fields by forming stereocomplexes on substrates. ${ }^{20-25}$ Porous it-PMMA thin films were prepared on quartz

${ }^{1}$ Department of Applied Chemistry, Graduate School of Engineering, Osaka University, 2-1 Yamada-oka, Suita, Osaka, Japan and ${ }^{2}$ The Center for Advanced Medical Engineering and Informatics, Osaka University, 2-2 Yamada-oka, Suita, Osaka, Japan

Correspondence: Dr M Akashi, Department of Applied Chemistry, Graduate School of Engineering, Osaka University, 2-1 Yamada-oka, Suita, Osaka 565-0871, Japan. E-mail: akashi@chem.eng.osaka-u.ac.jp

Received 30 August 2009; revised 1 November 2009; accepted 2 November 2009; published online 23 December 2009 
crystal microbalance (QCM), silica or glass substrates through layer-by-layer (LbL) assembly ${ }^{26}$ of it-PMMA/st-poly(methacrylic acid) (PMAA $)^{27-29}$ and the selective extraction of st-PMAA from it-PMMA/st-PMAA stereocomplex films, taking advantage of the different solubilities of each component polymer. The it-PMMA/ st-PMAA stereocomplex also forms a double-stranded helix similar to the aforementioned it-PMMA/st-PMMA stereocomplex. ${ }^{30}$ In addition, porous films prepared by LbL assembly have been compared with spin-coated it-PMMA films. The spin-coated films showed neither the specific recognition of st-polymethacrylate ${ }^{20}$ nor the template polymerization of methacrylic acid. ${ }^{22}$ Thus, it is concluded that these phenomena are particular to the macromolecularly porous films.

More recently, we observed partial it-PMMA crystallization, as well as st-PMAA incorporation, into porous films by XRD analyses. ${ }^{31,32}$ It was revealed that crystallized it-PMMA chains in films formed doublestranded helices. ${ }^{2,33}$ The crystallization of it-PMMA occurred merely by immersing the porous films in a mixed solvent of acetonitrile/water $(4 / 6, v / v)$ at room temperature, which is a different procedure and milder than conventional conditions. ${ }^{1-19}$ Furthermore, st-PMAA incorporation into porous it-PMMA films was analyzed at the molecular level by QCM. Porous it-PMMA films incorporated st-PMAA with increasing acetonitrile content in the st-PMAA solution. Therefore, it was concluded that acetonitrile was important for it-PMMA chain motion in porous films. st-PMAA was also incorporated into it-PMMA films driven by stereocomplex formation, even after it-PMMA crystallized partially, although the amount of st-PMAA incorporated into crystallized films was reduced as compared with the incorporation into porous films. ${ }^{32}$ However, both the changes in the morphology or properties of the films and the mechanisms responsible for these phenomena remained unclear.

In this study, we focused on the morphological changes of porous thin films during it-PMMA crystallization and the subsequent $s t$-PMAA incorporation. Films were characterized by scanning electron microscopy (SEM), AFM, X-ray photoelectron spectra and static contact angles. We also investigated whether the morphological changes of spin-coated films occur after immersion into a mixed solvent of acetonitrile/water in order to study the mechanisms of these interfacial rearrangements.

\section{EXPERIMENTAL PROCEDURE}

\section{Materials}

it-PMMA ${ }^{34}\left(M_{\mathrm{n}}=22900, M_{\mathrm{w}} / M_{\mathrm{n}}=1.21, m m: m r: r r=96: 2: 2\right)$ and $s t$-PMAA ${ }^{35}$ $\left(M_{\mathrm{n}}=33700, M_{\mathrm{w}} / M_{\mathrm{n}}=1.45\right.$, mm:mr:rr=1:5:94) were synthesized by conventional anionic polymerization. The number average molecular weights and distributions were measured by size exclusion chromatography using PMMA standards with a tetrahydrofuran eluant at $40{ }^{\circ} \mathrm{C}$ and a flow rate of $0.6 \mathrm{ml} \mathrm{min}{ }^{-1}$. Tacticities were analyzed from $\alpha$-methyl proton signals using $400-\mathrm{MHz}$ nuclear magnetic resonance (nitrobenzene- $d_{5}, 110^{\circ} \mathrm{C}$ ). Characterization of st-PMAA was achieved after the carboxyl group was methylated. Acetonitrile was purchased from Wako Pure Chemical Industries (Osaka, Japan). Ultrapure distilled water was provided by the MILLI-Q laboratory system (Millipore, Billerica, MA, USA).

\section{Film preparation}

An AT-cut QCM with a parent frequency of $9 \mathrm{MHz}$ was obtained from USI (Fukuoka, Japan) and used as the substrate. Frequency was monitored by an Iwatsu frequency counter (Model 53131A: Iwatsu Test Instruments Corp., Tokyo, Japan). The quartz crystal ( $9 \mathrm{~mm}$ diameter) was coated on both sides with mirror-like polished gold electrodes $(4.5 \mathrm{~mm}$ in diameter). At first, the QCM electrode was cleaned three times with a piranha solution, a mixed aqueous solution of $\mathrm{H}_{2} \mathrm{SO}_{4} / 40 \% \mathrm{H}_{2} \mathrm{O}_{2}(3 / 1, \mathrm{v} / \mathrm{v})$ for $1 \mathrm{~min}$, followed by rinsing with ultrapure water and drying with $\mathrm{N}_{2}$ gas. LbL films were prepared as follows: the substrate was alternatively immersed into an it-PMMA acetonitrile solution and an st-PMAA acetonitrile/water $(4 / 6, \mathrm{v} / \mathrm{v})$ solution at a concentration of 0.017 unitm for $5 \mathrm{~min}$ at $25^{\circ} \mathrm{C}$ each. The substrate was rinsed with each solvent, and dried with $\mathrm{N}_{2}$ gas whenever it was taken out from each solution. This alternative deposition step was repeated 16 times to fabricate stereocomplexes of $i t$-PMMA/st-PMAA on the substrates. Porous it-PMMA thin films were prepared by immersion into a $10 \mathrm{~mm} \mathrm{NaOH}$ aqueous solution. The porous films were immersed in mixed solvents of acetonitrile/water $(4 / 6, \mathrm{v} / \mathrm{v})$ for $10 \mathrm{~h}$, and then immersed in st-PMAA solutions of mixed acetonitrile/water $(4 / 6, v / v)$ solvents for $115 \mathrm{~min}^{32}$ Spin-coated it-PMMA films were prepared on the QCM at 1500 r.p.m. for 1 min with 0.051 unitm it-PMMA chloroform solutions. Acetonitrile was not used because it was a poor solvent for PMMA ${ }^{10}$ and could not dissolve it-PMMA completely at more than 0.017 unitM. Thus, chloroform, a good solvent for PMMA, was used to prepare the spin-coated films. The amount of $i t$-PMMA adsorbed onto the substrate was approximately $-1600 \mathrm{~Hz}$ per QCM. Spin-coated films were then immersed in acetonitrile/ water $(4 / 6, \mathrm{v} / \mathrm{v})$ for $10 \mathrm{~h}$.

\section{Measurements}

SEM images were obtained with a JSM-6701F (JEOL, Akishima, Japan) at an acceleration voltage of $5 \mathrm{kV}$ after osmium tetraoxide was spattered onto the surfaces of films at a thickness of approximately $5 \mathrm{~nm}$. AFM images were obtained with a JSPM-5400 (JEOL) that was operated in tapping mode in air at $25^{\circ} \mathrm{C}$. Scanning was performed using silicon cantilevers (NSC35, $\mu$-masch; resonance frequency: around $150 \mathrm{kHz}$; spring constant: $4.5 \mathrm{~N} \mathrm{~m}^{-1}$ ) within an area of $5 \times 5 \mu \mathrm{m}^{2}$ with a 512 scan line and a scan speed of $5.0 \mu \mathrm{m} \mathrm{s}^{-1}$. We did not perform any image processing other than the flat leveling. The mean square roughness $\left(R_{\mathrm{a}}\right)$ in the observed areas was estimated from the following equation, where $F(x, y)$ is the surface relative to the center plane, which is a flat plane parallel to the mean plane, and $L_{x}$ and $L_{y}$ are the dimensions of the surface.

$$
R_{a}=1 /\left(L_{x} L_{y}\right) \int_{0}^{L_{x}} \int_{0}^{L_{y}}|F(x, y)| \mathrm{d} x \mathrm{~d} y
$$

X-ray photoelectron spectroscopy (XPS) was obtained with a spectrometer (AXIS 165, Shimadzu-Kratos, Kyoto, Japan) using MgK $\alpha$ radiation. The typical operating conditions were as follows: X-ray gun, $12 \mathrm{kV}, 10 \mathrm{~mA}$; takeoff angle, $90^{\circ} \mathrm{C}$; pressure in the source chamber, $\sim 10^{-9}$ torr. The static contact angles of the thin films were measured by dropping ultrapure water on the films at $25^{\circ} \mathrm{C}$ with a DropMaster 500 (Kyowa InterFACE Science, Niiza, Japan). Contact angles were determined $10 \mathrm{~s}$ after applying the drop. The volume of water in the drop was $0.5 \mu \mathrm{l}$. All reported values represent the average of at least six measurements taken at different locations on the film surface.

\section{RESULTS AND DISCUSSION}

We used QCM analysis to calculate the amount of it-PMMA assembled on the gold substrate by Sauerbrey's equation. ${ }^{36}$ A typical QCM analysis is shown in Figure 1, and the time evolution means the period of immersion time in each solution or solvent. The stepwise stereocomplex assembly of it-PMMA/st-PMAA and the selective extraction of st-PMAA from assembled films were confirmed in previous papers. ${ }^{20,23,25,32}$ Interestingly, the elution of porous it-PMMA thin films was barely observed after the films were immersed into acetonitrile/water $(4 / 6, \mathrm{v} / \mathrm{v})$ for $10 \mathrm{~h}$, although the crystallized it-PMMA peaks were observed by XRD. ${ }^{31,32}$ These results indicate that the interfacial rearrangements of it-PMMA chains that occurred in films were driven by the mixed solvent, whereas it-PMMA crystallization was driven by annealing at high temperature or under compression in previous studies. ${ }^{11-19}$ The crystallized it-PMMA thin films can incorporate st-PMAA, most likely because further interfacial rearrangements also occurred in these films. Therefore, the morphological changes of the porous thin films during it-PMMA crystallization and the subsequent st-PMAA incorporation were initially 
analyzed by SEM and AFM. The same crystallized it-PMMA films, which corresponded to approximately $-1400 \mathrm{~Hz}$ per QCM, and the st-PMAA incorporated films were used in SEM and AFM observation.

We have observed several hemispherical outshoots on the surface of crystallized it-PMMA films by $\mathrm{AFM},{ }^{32}$ which implies that the morphological changes of the films occurred in a wide area as compared with the scanning area $(1 \times 1 \mu \mathrm{m})$ used in previous studies. ${ }^{20,29,32}$ Thus, SEM was used to observe the macroscopic deformation of porous thin films during it-PMMA crystallization and the subsequent

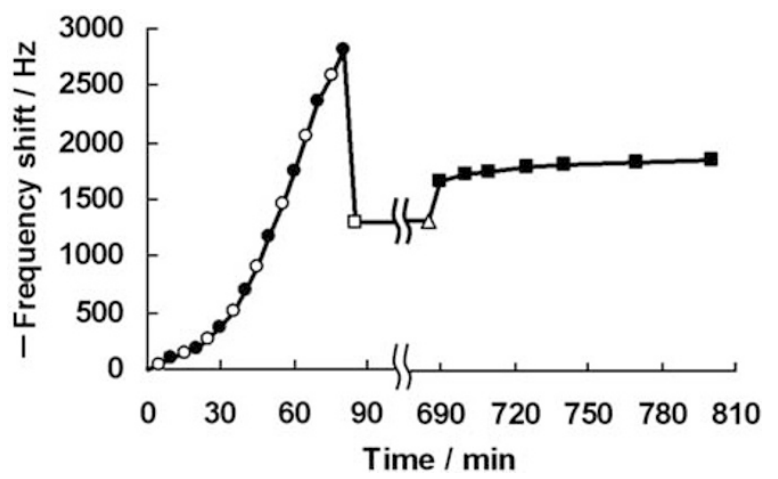

Figure 1 Typical QCM analysis of the layer-by-layer assembly, st-PMAA extraction, isotactic it-PMMA crystallization and subsequent st-PMAA incorporation. it-PMMA (white circles) in acetonitrile and st-PMAA (black circles) in acetonitrile/water $(4 / 6, \mathrm{v} / \mathrm{v})$ were alternately assembled on a QCM substrate at 0.017 unitm at $25^{\circ} \mathrm{C}$. Porous it-PMMA films were prepared using $10 \mathrm{~mm} \mathrm{NaOH}(\mathrm{aq})$ (white square). The following it-PMMA crystallization occurred in a mixed solvent of acetonitrile/water (4/6, v/v) (white triangle). The last st-PMAA incorporation was observed at 0.017 unitm at $25^{\circ} \mathrm{C}$ (black squares).
st-PMAA incorporation. Figure 2 shows SEM images of crystallized $i t$-PMMA films and st-PMAA incorporated films after $10 \mathrm{~h}$ of immersion in acetonitrile/water $(4 / 6, v / v)$. Dotted aggregates of crystallized it-PMMA and networks of the it-PMMA/st-PMAA mixed assembly broadened evenly at the submillimeter scale (Figures $2 \mathrm{a}$ and $\mathrm{b}$ ). The patterns were not observed on the surface of a bare QCM substrate and porous it-PMMA films (Supplementary Figure S1). In the magnified view (tilted at 40-degree angles), some dots were connected to form big outshoots on the crystallized it-PMMA films (Figure 2c), and some isolated outshoots were also observed on st-PMAA incorporated films after it-PMMA crystallization (Figure 2d). However, most regions of the crystallized it-PMMA films and st-PMAAincorporated films formed dots and networks, respectively, although the configurations of these assemblies cannot be controlled yet. This morphological change from dots to networks likely resulted from an increased polymer density of films during the incorporation of st-PMAA.

AFM analysis was used to calculate both the height of the assemblies and the surface roughness of films, which was difficult to measure by SEM. Figure 3 shows AFM images of crystallized it-PMMA films and $s t$-PMAA incorporated films after it PMMA crystallization. Hemispherical outshoots of crystallized it PMMA, which were several hundred nanometers high, were arranged in a dot pattern on films (Figure 3a), whereas porous films were relatively flat (Supplementary Figure S2). The mean square roughness $\left(R_{\mathrm{a}}\right)$ of the crystallized itPMMA films was $53 \mathrm{~nm}$, although the $R_{\mathrm{a}}$ of the smooth parts $(0.3 \times 0.3 \mu \mathrm{m})$ of films was $3.3 \pm 0.2 \mathrm{~nm}(n=3)$. This value was more similar to that of a bare QCM substrate $(3.1 \mathrm{~nm})$ than that of porous it-PMMA films $(17 \mathrm{~nm})$ (Supplementary Figure S2), suggesting that the bare gold surface is exposed. In addition, the outshoots of crystallized it-PMMA films, which corresponded to approximately $-700 \mathrm{~Hz}$ per QCM (Supplementary Figure S2), were smaller and more
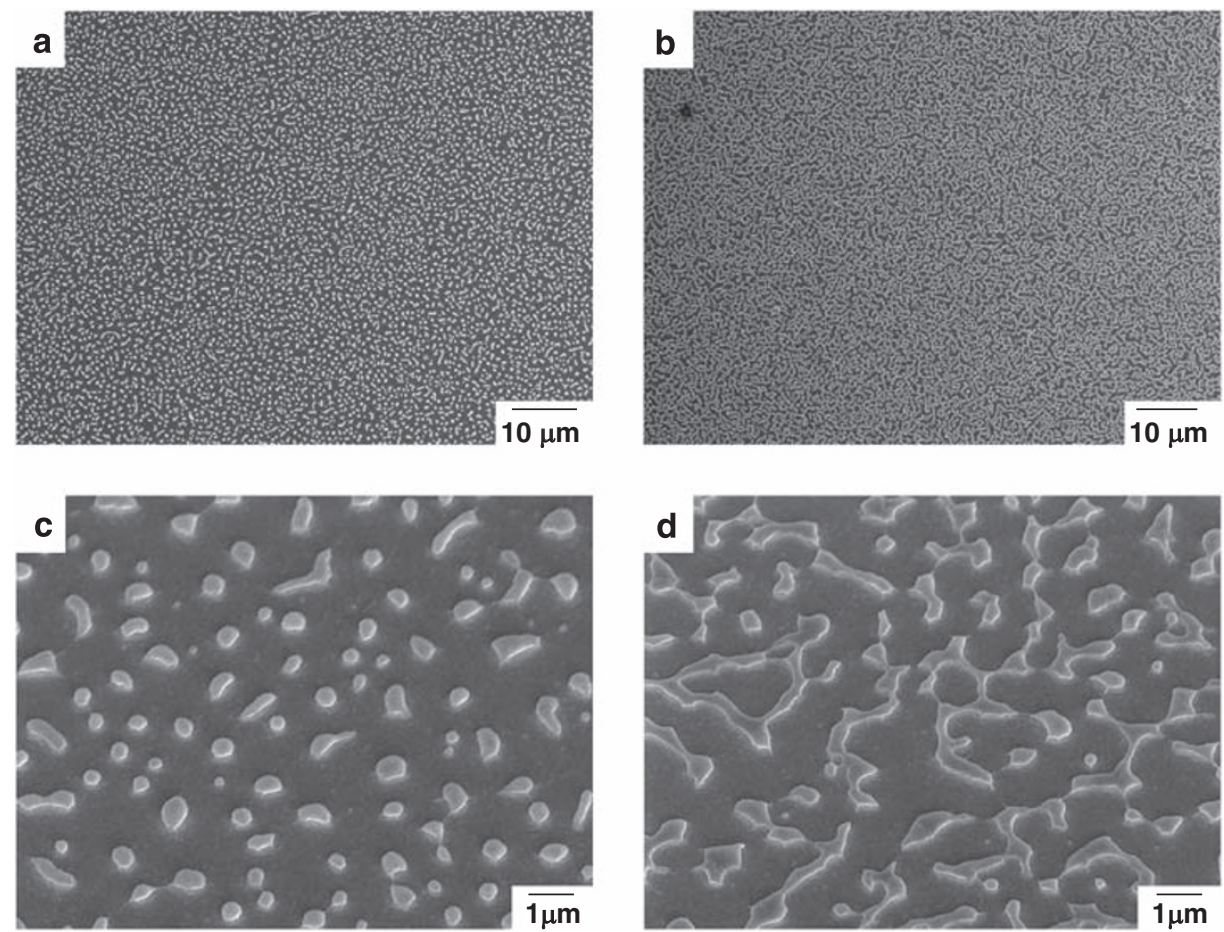

Figure 2 SEM images of crystallized it-PMAA films (a, c) and st-PMAA incorporated films (b, d) after $10 \mathrm{~h}$ of immersion in acetonitrile/water (4/6, v/v). (a, b) Top view. (c, d) Tilted view. 

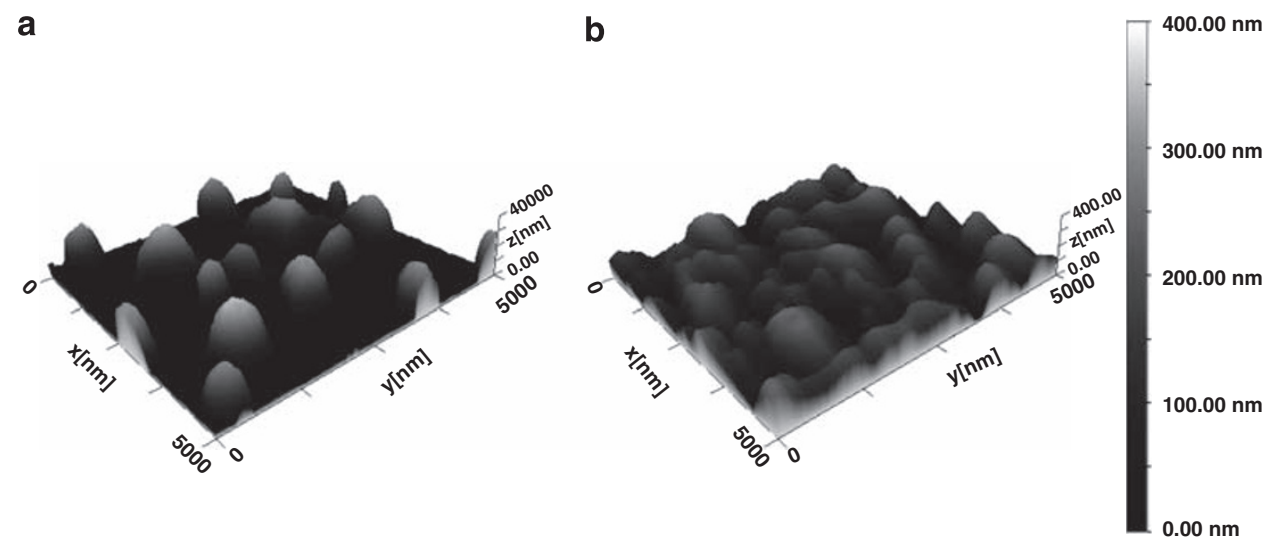

Figure 3 AFM images of crystallized it-PMAA films (a) and st-PMAA incorporated films (b) after $10 \mathrm{~h}$ of immersion in acetonitrile/water (4/6, v/v).

than that of the crystallized films in Figure 3a $(-1400 \mathrm{~Hz}$ per QCM), which implies that film thickness is one of the important parameters for morphological changes of it-PMMA films. Furthermore, a similar dot pattern was also observed on crystallized it-PMMA $(-700 \mathrm{~Hz}$ per QCM) after $40 \mathrm{~h}$ of immersion in acetonitrile/water (4/6, v/v) (Supplementary Figure S2). On the other hand, networks of agglomerates composed of crystallized it-PMMA and stereocomplexes were observed on the surface of st-PMAA incorporated films (Figure 3b), and the heights of these assemblies were not significantly different from that of crystallized it-PMMA films. Therefore, the polymer chains in films likely spread in a horizontal direction during $s t$-PMAA incorporation. Indeed, the $R_{\mathrm{a}}$ of $s t$-PMAA-incorporated films was $46 \mathrm{~nm}$, but the $R_{\mathrm{a}}$ of the smooth parts $(0.3 \times 0.3 \mu \mathrm{m})$ was $3.8 \pm 0.5 \mathrm{~nm}(n=3)$. This morphological change in films indicated that some noncrystalline parts of it-PMMA could incorporate st-PMAA, and that a rearrangement of the partially crystallized it-PMMA might occur on the film surface.

Next, we were interested in the changes in properties of porous it-PMMA films. The deformation of films during it-PMMA crystallization would dynamically change the film thickness. XPS analysis is a common tool to confirm chemical bonds on a surface at $\sim 10 \mathrm{~nm}$ of the measured depth. The XPS spectra of a bare QCM substrate, porous it-PMMA films and crystallized it-PMMA films are shown in Figure 4. Distinct $\mathrm{Au} 4 \mathrm{f}$ peaks at around 84.1 and $87.7 \mathrm{eV}$ were observed on the QCM substrate (Figure 4a). In contrast, these Au peaks were not observed on the surface of porous films (Figure $4 \mathrm{~b}$ ), showing that the thickness of porous films was more than $10 \mathrm{~nm}$, and that the substrate was evenly covered with film. In a previous paper, ${ }^{20}$ the thickness of porous it-PMMA films was determined to be $44 \mathrm{~nm}$ by AFM scratching mode, which corresponded to approximately $-800 \mathrm{~Hz}$ per QCM. Therefore, it-PMMA film thickness was calculated as $83 \mathrm{~nm}(-1500 \mathrm{~Hz}$ per QCM) in this study (Figure 1), according to a constant rate of $0.055 \mathrm{~nm} / \mathrm{Hz}$. Note that the intensity of $\mathrm{Au} 4 \mathrm{f}$ peaks on the surface of crystallized it-PMMA films was about two-thirds of that of the QCM substrate (Figure 4c), and that the heights of the outshoots on the crystallized it-PMMA films reached several hundred nanometers (Figure 3a), where Au peaks should not be detected. Thus, the film thickness of the smooth parts became less than $10 \mathrm{~nm}$ after it-PMMA films were immersed in acetonitrile/water $(4 / 6, \mathrm{v} / \mathrm{v})$. These results confirmed that the homogeneously broadened it-PMMA in porous films became localized because of its crystallization, which brought about differences in the polymer density of films.

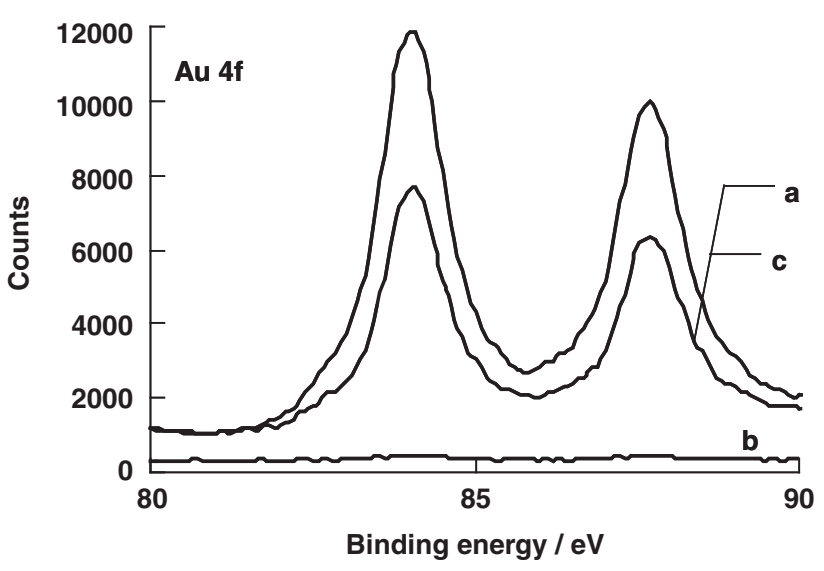

Figure 4 XPS in the region of the gold element of a bare quartz crystal microbalance substrate (a), porous it-PMMA films (b) and crystallized it-PMMA films (c) after $10 \mathrm{~h}$ of immersion in acetonitrile/water (4/6, v/v).

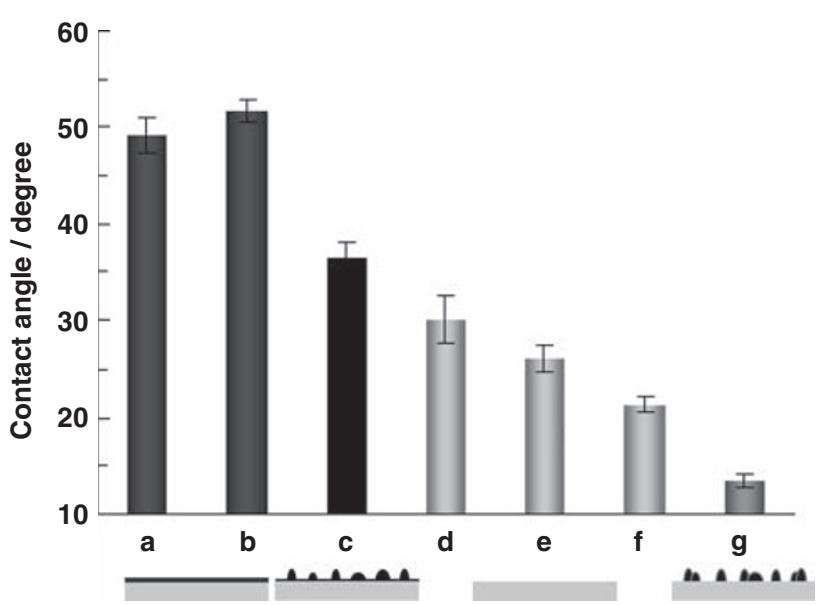

Figure 5 Static contact angles of porous it-PMMA films as prepared (a) and after $10 \mathrm{~h}$ of immersion in water (b), crystallized it-PMMA films after $10 \mathrm{~h}$ of immersion in acetonitrile/water (4/6, v/v) (c), stereocomplex films (d) and st-PMAA incorporated films just after st-PMAA extraction (e) and after $10 \mathrm{~h}$ of immersion in water ( $f$ ) and acetonitrile/water $(4 / 6, v / v)(g)$. 
Furthermore, film characteristics were analyzed on the millimeter scale with static contact angles, which have been used to confirm stepwise stereocomplex formation during LbL assembly. ${ }^{29}$ We thought that the contact angles of each film would change according to its surface components or shapes. Figure 5 shows the dependence of static contact angles on various film surfaces. Surface components and polymer conformations were analyzed by attenuated total reflectionIR (Supplementary Figure S3). ${ }^{20}$ The mean angles of porous it-PMMA films as prepared and after $10 \mathrm{~h}$ of immersion in water were $49.2 \pm 1.9^{\circ}$ and $51.7 \pm 1.0^{\circ}$, respectively (Figures $5 \mathrm{a}$ and $\mathrm{b}$ ). This is reasonable because XRD analyses revealed that no structural changes of porous it-PMMA films occurred in water. ${ }^{32}$ In contrast, the angles of crystallized it-PMMA films after $10 \mathrm{~h}$ immersion in acetonitrile/water (4/6, v/v) was $36.5 \pm 1.6^{\circ}$ (Figure 5c). These differences likely resulted from a surface morphology change of the thin films, because both films were composed only of it-PMMA and the two porous films were smooth compared with crystallized films (Figure 3a, Supplementary Figure S2). We should also consider that the film thickness of the smooth parts in crystallized it-PMMA films was less than $10 \mathrm{~nm}$ and the gold surface of QCM is exposed, according to XPS results (Figure 4c). Although the mean angle of a bare QCM substrate was 69.2 $\pm 1.4^{\circ}$, Burton and Bhushan ${ }^{37}$ reported
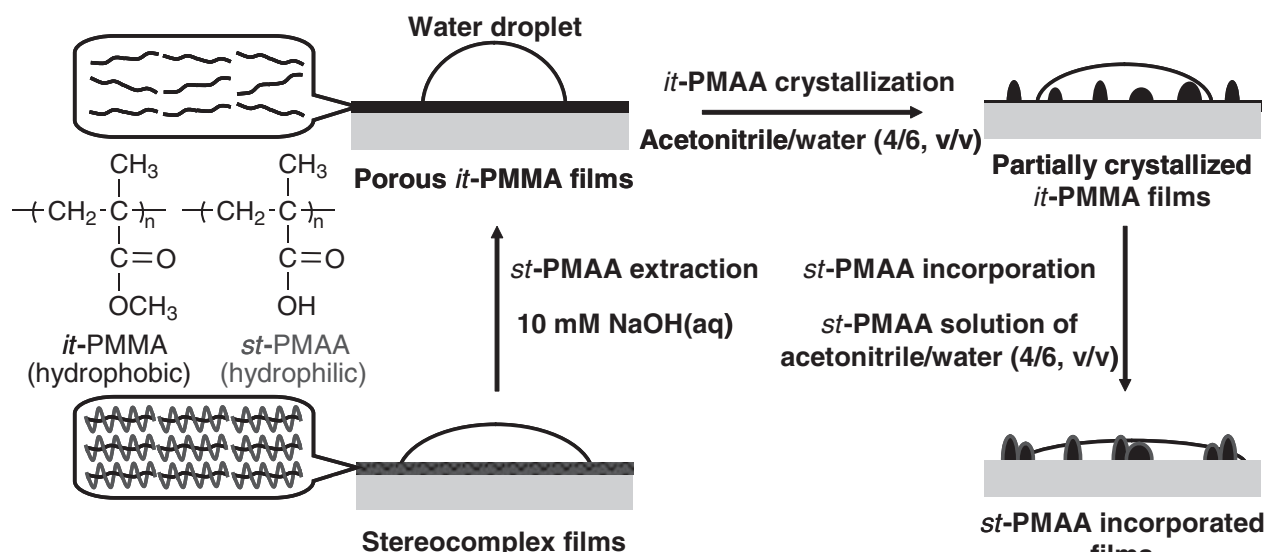

Stereocomplex films films

Figure 6 Schematic illustration of the morphological changes of macromolecularly porous thin films in it-PMMA crystallization and st-PMAA incorporation.
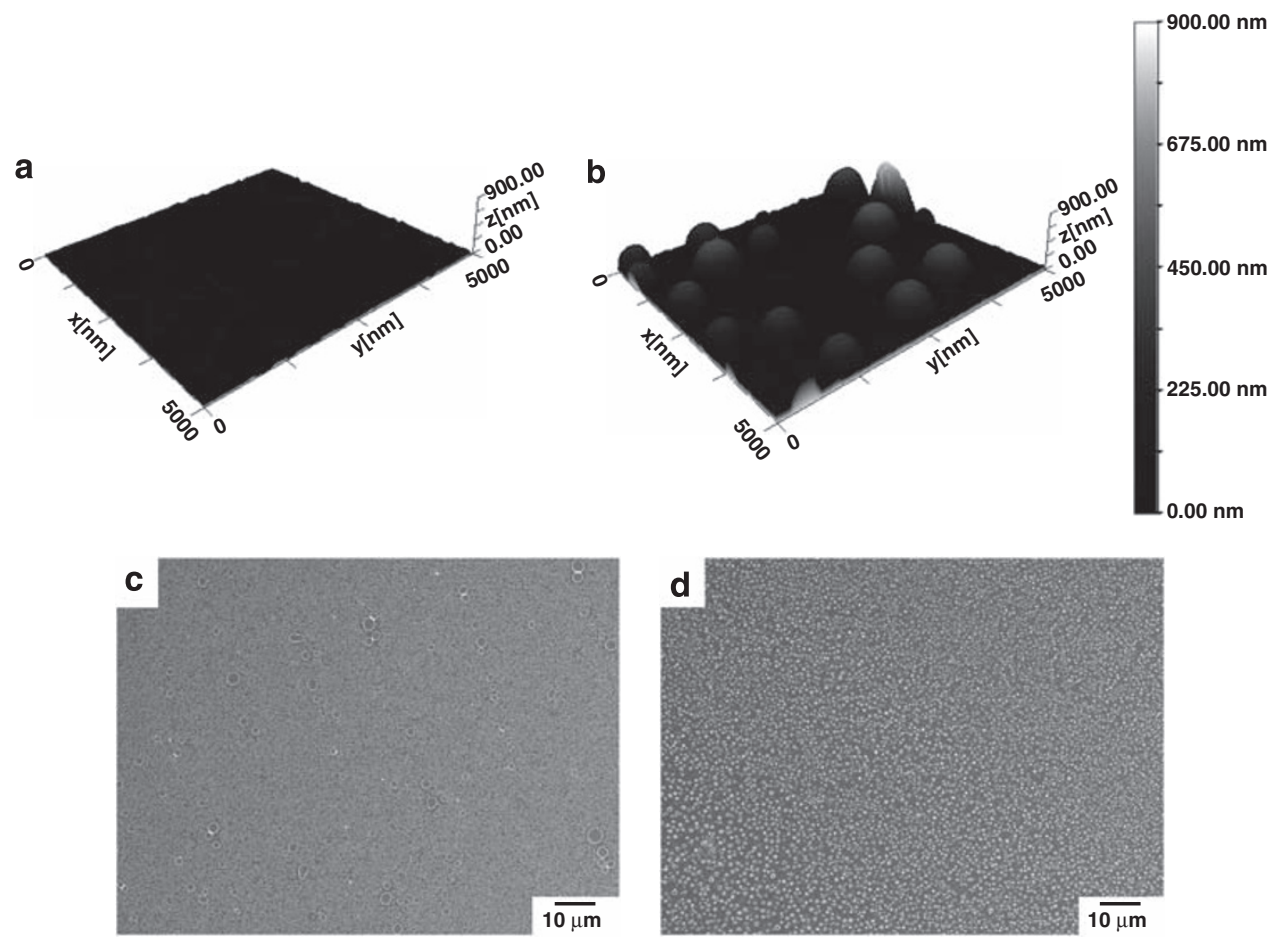

Figure $7 \mathrm{AFM}$ and SEM images of spin-coated it-PMMA films prepared from a chloroform solution $(\mathbf{a}, \mathbf{c})$ and after $10 \mathrm{~h}$ of immersion in acetonitrile/water $(4 / 6, v / v)(b, d)$. 
that increasing roughness on hydrophilic surfaces, such as the patterned PMMA surface, decreased the contact angle, which was consistent with these results.

This tendency was also observed in the case of stereocomplex films. The contact angle of the original LbL films was $30.2 \pm 2.5^{\circ}$, and the angles of $s t$-PMAA incorporated films after st-PMAA extraction and a subsequent $10 \mathrm{~h}$ of immersion in water were $26.4 \pm 1.3^{\circ}$ and $21.4 \pm 0.8^{\circ}$, respectively (Figures $5 \mathrm{~d}-\mathrm{f}$ ). The mean values of stereocomplex films were smaller than those of porous it-PMMA films, ${ }^{29}$ because the hydrophobic it-PMMA is buried in the helical structure of hydrophilic st-PMAA in the stereocomplex model. ${ }^{30} s t$-PMAA incorporated films remained flat (Supplementary Figure S2), although the slow crystallization of it-PMMA also occurred during the incorporation of $s t$-PMAA. ${ }^{31}$ Therefore, the fast st-PMMA incorporation by stereocomplexation might prevent film deformation because of it-PMMA crystallization. On the other hand, the angle of st-PMAA incorporated films after it-PMMA crystallization was $13.6 \pm 0.7^{\circ}$ (Figure $5 \mathrm{~g}$ ). It is indicated that the surface of films was covered with stereocomplexes (Figure 6), although the it-PMMA inside the aggregates is densely packed and loses the ability to incorporate st-PMAA. It also remains unclear whether st-PMAA adsorbed both on the crystallized it-PMMA outshoots and on the smooth domains of films. These tendencies of static contact angles also corresponded to the relatively regular surface profile at the submillimeter scale, which was observed by SEM (Figures $2 \mathrm{a}$ and $\mathrm{b}$ ).

We were also interested in whether ordinary it-PMMA films would form outshoots after immersion into a mixed solvent of acetonitrile/ water. Spin-coated it-PMMA films were prepared on the QCM substrate from the chloroform solution as described in the experimental procedure section. Figure 7 shows the AFM and SEM images of spin-coated it-PMMA films as prepared and after immersed in acetonitrile/water $(4 / 6, \mathrm{v} / \mathrm{v})$ for $10 \mathrm{~h}$. The $R_{\mathrm{a}}$ of spin-coated films was $8.4 \mathrm{~nm}$ and the film surface was relatively smooth (Figure 7a). A few big craters were formed on the films, most likely because of the evaporation of chloroform (Figure 7c). The QCM frequency shift was a few hertz after $10 \mathrm{~h}$ of immersion in acetonitrile/water $(4 / 6, \mathrm{v} / \mathrm{v})$, which implies that the spin-coated films did not dissolve in the mixed solvent either. Semispherical outshoots were also observed on films after immersion (Figure $7 \mathrm{~b}$ ), and dotted aggregates of it-PMMA broadened evenly at the submillimeter scale (Figure $7 \mathrm{~d}$ ). The same tendency of crystallized it-PMMA films was obtained by LbL assembly, even though the $R_{\mathrm{a}}$ of films $(82 \mathrm{~nm})$ was much greater than that of it-PMMA films from LbL assembly $(32 \mathrm{~nm})$. The surface roughness derived by the crystallization of it-PMMA is dependent on the initial thickness, roughness or morphology of the films, such as the cratered surface. These results indicate that the formation of these hemispherical outshoots would occur by rearrangements of it-PMMA chains in thin films.

\section{CONCLUSIONS}

We investigated the morphological changes of porous thin films on a QCM substrate during it-PMMA crystallization and the subsequent $s t$-PMAA incorporation. Dotted aggregates of crystallized it-PMMA appeared on films on SEM and AFM images, although the films were not dissolved in a mixed solvent of acetonitrile/water. Gold substrate peaks were observed on crystallized it-PMMA films by XPS. Therefore, this indicated that the adsorbed it-PMMA spontaneously localized in films to reform the surface profile. These dotted it-PMMA aggregates were also observed when spin-coated films were immersed in the mixed solvent, suggesting that this immersion method is a simple and different approach to film deformation, as compared with previous studies. On the other hand, networks of crystallized it-PMMA and the stereocomplex appeared on st-PMAA-incorporated films. In this way, the design and restructuring of self-assembled films at the nano or micrometer scale were achieved through self-organization and stereocomplex formation of stereoregular polymethacrylates.

\section{ACKNOWLEDGEMENTS}

This work was partially supported by a Grant-in-Aid for Scientific Research (no.19650123) from the Japan Society of the Promotion of Science. We acknowledge Drs T Kida, J Watanabe, M Matsusaki, T Akagi, C Hongo, and T Waku, Osaka University, for their fruitful discussions.

1 Fox, T. G., Garret, B. S., Goode, W. E., Grantch, S., Kincaid, J. F. \& Spell, A. Crystalline polymers of methyl methacrylate. J. Am. Chem. Soc. 80, 1768-1769 (1958).

2 Kusanagi, H., Tadokoro, H. \& Chatani, Y. Double stranded helix of isotactic poly(methyl methacrylate). Macromolecules 9, 531-532 (1976).

3 Kusuyama, H., Takase, M., Higashihata, Y., Tseng, H. T., Chatani, Y. \& Tadokoro, H. Structural change of st-PMMA on drawing, absorption, and desorption of solvents. Polymer 23, 1256-1258 (1982).

4 Spevacek, J. \& Schneider, B. Aggregation of stereoregular poly(methyl methacrylates). Adv. Colloid Interface Sci. 27, 81-150 (1987).

5 te Nijenhuis, K. Thermoreversible networks. 4. poly (methyl methacrylate). Adv. Polym. Sci. 130, 67-81 (1997).

6 Hatada, K. \& Kitayama, T. Structurally controlled polymerizations of methacrylates and acrylates. Polym. Int. 49, 11-47 (2000).

7 Schomaker, E. \& Challa, G. Complexation of stereoregular poly(methyl methacrylates). 14. The basic structure of the stereocomplex of isotactic and syndiotactic poly(methyl methacrylate). Macromolecules 22, 3337-3341 (1989).

8 Liu, J., Zhang, Y., Zhang, J., Shen, D., Guo, Q. Takahashi, I. \& Yan, S. Stereocomplexation and monolayer morphologies of a stereoregular poly(methyl methacrylate) mixture formed at the air/water surface. J. Phys. Chem. C 111, 6488-6494 (2007).

9 Kumaki, J., Kawauchi, T., Okoshi, K., Kusanagi, H. \& Yashima, E. Supramolecular herical structure of the stereocomplex composed of complementary isotactic and syndiotactic poly(methyl methacrylate)s as revealed by atomic force microscopy. Angew. Chem. Int. Edn. Engl. 46, 5348-5351 (2007).

10 Wunderlich, W. in Polymer Handbook (eds. Brandrup, J. \& Immergut, E. H.) Ch. 5, V77-V80 (John Wiley \& Sons, New York, 1989).

11 Klement, J. J. \& Geil, P. H. Deformation and annealing behavior. 3. Thin films of polycarbonate, isotactic polymethyl methacrylate, and isotactic polystyrene. J. Macromol. Sci. B 6, 31-56 (1972).

12 de Boer, A., van Ekenstein, G. O. R. A. \& Challa, G. Crystallization of isotactic poly(methyl methacrylate) from the melt. Polymer 16, 930-932 (1975).

13 Schneider, B., Stokr, J., Spevacek, J. \& Baldrian, J. Infrared spectra and crystallinity of isotactic poly(methyl methacrylate) and of its deuterated analogues. Makromol. Chem. 188, 2705-2711 (1987).

14 Dybal, J. \& Krimm, S. Normal-mode analysis of infrared and raman spectra of crystalline isotactic poly(methyl methacrylate). Macromolecules 23, 1301-1308 (1990).

15 Brinkhuis, R. H. R. \& Schouten, A. J. Thin-film behavior of poly(methyl methacrylates). 2. An FT-IR study of Langmuir-Blodgett films of isotactic PMMA. Macromolecules 24, 1496-1504 (1991).

16 Brinkhuis, R. H. R. \& Schouten, A. J. Thin-film behavior of poly(methyl methacrylates). 3. Epitaxial crystallization in thin films of isotactic poly(methyl methacrylate) using crystalline Langmuir-Blodgett layers. Macromolecules 25, 2717-2724 (1992).

17 Zhou, D., Li, L., Che, B., Cao, Q., Lu, Y. \& Xue, G. Metastable isotactic poly(methyl methacrylate) prepared by freeze-extracting solutions in poly(ethylene glycol). Macromolecules 37, 4744-4747 (2004).

18 Kumaki, J., Kawauchi, T. \& Yashima, E. Two-demensional folded chain crystals of a synthetic polymer in a Langmuir-Blodgett film. J. Am. Chem. Soc. 127, 5788-5789 (2005).

19 Liu, J., Wang, J., Li, H., Shen, D., Zhang, J., Ozaki, Y. \& Yan, S. Epitaxial crystallization of isotactic poly(methyl methacrylate) on highly oriented polyethylene. J. Phys. Chem. B 110, 738-742 (2006).

20 Serizawa, T., Hamada, K., Kitayama, T. \& Akashi, M. Recognition of stereoregular polymers by using structurally regulated ultrathin polymer films. Angew. Chem. Int. Edn. Engl. 42, 1118-1121 (2003).

21 Serizawa, T., Hamada, K. \& Akashi, M. Polymerization within a molecular-scale stereoregular template. Nature 429, 52-55 (2004).

22 Hamada, K., Serizawa, T. \& Akashi, M. Template polymerization using artificial double strands. Macromolecules 38, 6759-6761 (2005).

23 Ajiro, H., Kamei, D. \& Akashi, M. Methacrylic acid and methyl methacrylate oligomers adsorbed to porous isotactic poly (methyl methacrylate) ultrathin filims and mechanistic studies of living template polymerization. J. Polym. Sci., Part A: Polym. Chem. 17, 5879-5886 (2008). 
24 Ajiro, H., Kamei, D. \& Akashi, M. Macroporous silicagel substrate for stereoregular template polymerization of methacrylic acid using stereocomplex assembled thin films. Polym. J. 41, 90-93 (2009)

25 Ajiro, H., Kamei, D. \& Akashi, M. Mechanistic studies on template polymerization in porous isotactic poly(methyl methacrylate) thin films by radical polymerization and postpolymerization of methacrylate derivatives. Macromolecules 42, 3019-3025 (2009).

26 Decher, G. Fuzzy nanoassemblies: toward layered polymeric multicomposites. Science 277, 1232-1237 (1997).

27 Lohmeyer, J. H. G. M., Kransen, G., Tan, Y. Y. \& Challa, G. Stereoassociation between poly(methyl methacrylate) and poly(methacrylic acid). Polym. Lett. Edn. 13, 725-729 (1975).

28 Lohmeyer, J. H. G. M., Tan, Y. Y., Lako, P. \& Challa, G. Stereoselective association between isotactic poly(methyl methacrylate) and syndiotactic poly(methacrylic acid). Polymer 19, 1171-1175 (1978).

29 Serizawa, T., Hamada, K., Kitayama, T., Katsukawa, K., Hatada, K. \& Akashi, M. Stepwise assembly of isotactic poly(methyl methacrylate) and syndiotactic poly(methacrylic acid) on a substrate. Langmuir 16, 7112-7115 (2000).

30 Bosscher, F., ten Brinke, G. \& Challa, G. Association of stereoregular poly(methyl methacrylates). 6 . Double-stranded helical structure of the stereocomplex of isotactic and syndiotactic poly(methyl methacrylate). Macromolecules 15, 1442-1444 (1982).
31 Kamei, D., Ajiro, H., Hongo, C. \& Akashi, M. Dynamics of polymer chains in porous thin films prepared by layer-by-layer assembly of isotactic poly(methyl methacrylate) and syndiotactic poly(methacrylic acid). Chem. Lett. 37, 332-333 (2008).

32 Kamei, D., Ajiro, H., Hongo, C. \& Akashi, M. Solvent effects on isotactic poly(methyl methacrylate) crystallization and syndiotactic poly(methacrylic acid) incorporation in porous thin films prepared by stepwise stereocomplex assembly. Langmuir 25, 280-285 (2009).

33 Kusy, R. P. Determination of the heat of fusion of isotactic poly(methyl methacrylate). J. Polym. Sci., Part A: Polym. Chem. 14, 1527-1536 (1976).

34 Hatada, K., Ute, K., Tanaka, K., Kitayama, T. \& Okamoto, Y. Preparation of highly isotactic poly(methyl methacrylate) of low polydispersity. Polym. J. 17, 977-980 (1985).

35 Kitayama, T., He, S., Hironaka, Y., lijima, T. \& Hatada, K. Preparation of highly stereoregular poly(methacrylic acid) by stereospecific anionic polymerization of trimethylsilyl methacrylate. Polym. J. 27, 314-318 (1995).

36 Sauerbrey, G. The use of quarts oscillators for weighing thin layers and for microweighing. Z. Phys. 155, 206-222 (1959)

37 Burton, Z. \& Bhushan, B. Hidrophobicity, adhesion, and friction properties of nanopatterned polymers and scale dependence for micro- and nanoelectromechanical systems. Nano Lett. 5, 1607-1613 (2005).

Supplementary Information accompanies the paper on Polymer Journal website (http://www.nature.com/pj) 